\title{
HSC Chemistry
}

Reaction and Equilibrium Software with extensive Thermochemical Database
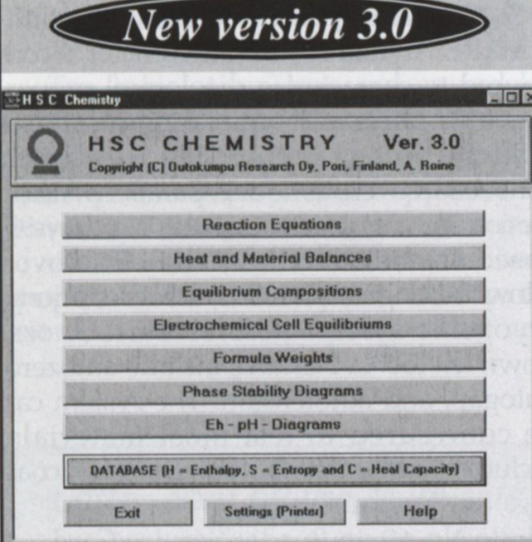

The HSC 3.0 has many brand new features and properties requested by HSC users:

1. The new table editor offers many extremely useful spreadsheet type features such as number formatting, cell references, formulae, etc. These can be applied, eg. to maintain the material balance in the Heat Balance module.

2. The new graphical routines add several new user-friendly editing and formatting capabilities, with less limitations.

3. The calculation capability of equilibrium and $\mathrm{EpH}$ modules has been improved as well as the calculation speed of the Gibbs-module.

4. The totally new construction of the database enables flexible change of active databases as well as direct access to the database from most of the calculation modules.

5. The number of species in the database has been increased from 7600 to more than 11000 .

6. Some 60 minor improvements will facilitate calculations and the familiar HSC 2.0 style user interface minimizes training requirements.

Ask for a list of HSC 3.0 new features:

\section{ESM Software:}

Tel: +1 - $513-738-4773$

http://www.esm-software.com

WindowChem Software:

Tel: +1 - $707-864-0845$

Fax: +1 - 707 - $864-2815$

Outokumpu Research Oy

P.O. Box 60

FIN-28101 Pori, Finland

Tel: +358 - $2-626-6111$

Fax: +358 - $2-626-5310$

E-mail: hsc@outokumpu.fi

www.outokumpu.fi/hsc
Figures appearing in EDITOR'S CHOICE are those arising from materials research which strike the editor's fancy as being aesthetically appealing and eye-catching. No further criteria are applied and none should be assumed. When taken out of context, such figures often evoke images beyond and unrelated to the original meaning. Submissions of candidate figures are welcome and should include a complete source citation, a photocopy of the report in which it appears (or will appear), and a reproduction-quality original drawing or photograph of the figure in question.

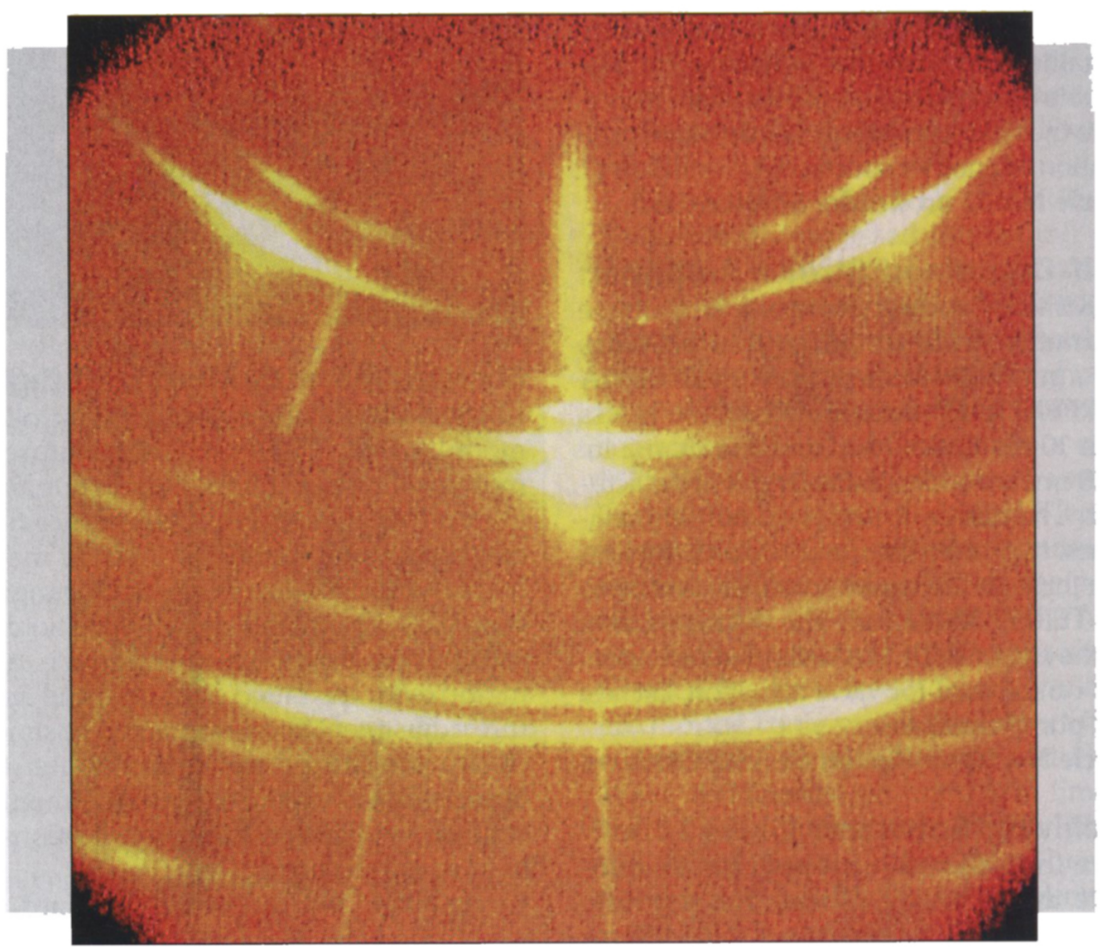

Staring back at you in this month's EDITOR'S CHOICE is the specter of a jack-olantern awaiting All Hallows' Eve. This sinister visage is clearly more trick than treat. The pumpkin-esque likeness is in fact a real x-ray diffraction pattern in costume, so to speak. Its colors are not a transparent attempt to mimic a squash but really correspond to an $\mathrm{x}$-ray intensity scale. The facial features are segments of conic sections, formed as the incomplete cones of diffracted copper $\mathrm{K} \alpha \mathrm{x}$-rays corresponding to particular lattice reflections from the polycrystalline sample intersect a two-dimensional (area) detector. The diffracting sample is a film of antiferroelectric tin-doped lead-zirconate-titanate (PZST) on a platinum-coated silicon-oxide-on-silicon substrate. Its overall pseudocubic lattice, in conjunction with a textured pseudo- $\langle 111\rangle$-oriented microstructure, "carved" out the primary features-eyes, nose, and mouth. But, there's more. The $\langle 111\rangle$-oriented platinum film accounts for the extra bright light emanating from under the nose. And, ghosts from the [100] underlying silicon appear as thin radial spokes (not spooks) lurking under the mouth and the right eye. The PZST (pronounced pssst) film in the antiferroelectric phase is actually orthorhombic as confirmed by the pair of unraised eyebrows. The researchers, B.A. Tuttle, H.N. Al-Shareef, M.A. Rodriguez, P.G. Clem, D. Tallant, and T.J. Garino of Sandia National Laboratories, ${ }^{1}$ could have forecast their spooky result had they only realized that a concoction whose major ingredient is sugar of lead (a good substitute for eyeof-newt), that is baked at inferno-like temperatures, and that is spun (presumably with fitting incantations) at a dizzying $3500 \mathrm{rpm}$, is a witch's brew indeed. They of course characterize the process as a hybrid metalorganic decomposition technique. Readers will just have to wait for their paper to appear and decide for themselves.

1B.A. Tuttle, et al., "Dielectric behavior and phase stability of solution deposited $\mathrm{Pb}(\mathrm{Zr}, \mathrm{Sn}, \mathrm{Ti}) \mathrm{O}_{3}$ thin films," preprint (to be submitted to J. Am. Ceram. Soc.). 